\title{
The Effect of UV Irradiation to a-C:H on Friction and Wear Properties under PAO Oil Lubrication Including MoDTC and ZnDTP
}

\author{
Mohd Taufik bin Taib*, Noritsugu Umehara, Takayuki Tokoroyama and Motoyuki Murashima \\ Department of Micro-Nano Mechanical Science and Engineering, Nagoya University, \\ Furo-cho, Chikusa-ku, Nagoya, Aichi 464-8603, Japan \\ *Corresponding author: Mohd Taufik bin Taib (mtaufik@utem.edu.my)
}

Manuscript received 15 January 2018; accepted 02 May 2018; published 15 July 2018

Presented at the 6th World Tribology Congress 2017 Beijing, September 2017

\begin{abstract}
One of the solutions to reduce friction between two sliding surfaces in automobile engine is by applying DLC coating to engine components. However, it is critical that the effect of lubricant additives to DLC coating to be clarified before hands as to avoid components failure. In this study, tribological friction test between SUJ2 balls and as-deposited plus UV irradiated a-C:H coatings was conducted to clarify the effect of ultraviolet irradiation to DLC coating in four different additives added lubricant oils. AFM, nanoindentation hardness test, ellipsometery, Zygo, and EDS-SEM were used to investigate the effect of UV irradiation to a-C:H DLC before and after friction test. Prior the friction test, the results showed that UV irradiation presented no significant change in terms of hardness and roughness but the irradiation did penetrate into topmost surface of the a-C:H coating to several degree and created dangling bonds available to interact with lubricant additives elements. Friction test results showed that UV irradiated a-C:H coatings presented lower friction coefficient than as deposited a-C:H coatings. Worn surface analysis revealed that UV irradiated a-C:H coatings attracted more lubricant additives element to attach on its surface thus created thicker tribofilm on its own surface and its counter materials, resulted in lower friction coefficient than the as-deposited a-C:H coatings.
\end{abstract}

\section{Keywords}

DLC, a-C:H coating, oil additives, lubricants, tribofilm, UV irradiation

\section{Introduction}

From the $100 \%$ of fuel that being poured into one vehicle, $33 \%$ of the chemical energy converted will be transformed into friction, and $17 \%$ of the previous percentage will be converted into engine and transmission friction losses [1]. One of the solutions to reduce these losses is by applying diamond like carbon (DLC) to engine components so that higher engine performance, fuel efficiency and also harmful emission gas reduction can be achieved. DLC is an amorphous material which is a combination of both sp2 and sp3 structure and as a result, a superior material that has the properties of low in friction, high hardness, chemically inert and highly wearresist. However, in order to apply DLC in engine components, one problem might happen which is the incompatibilities between DLC and the lubricant additives. This is due to current commercial lubricant containing various type of additives, designed only to cater the contact between metal to metal and not in between DLC and metal. If this problem is not solved, it ultimately will cause DLC coated parts failure.

Anti-oxidant and anti-wear properties of Zinc dialkyldithioposphate (ZnDTP) is one of oil additives that has been extensively used for a long time. In recent times, there are numerous studies regarding on the tribological characteristics of DLC films in ZnDTP oil lubrication [2-9]. However, the reaction between DLC and ZnDTP are very much depending on the type of the DLC film used. Studies showed that there was ZnDTP derived tribofilm formed on the DLC film [4-7] and there was also some that reported on the non-existence of $\mathrm{ZnDTP}$ derived tribofilm on sliding surface of DLC film [8,9].

Another studies reported that due to the existence of MoDTC in lubricant oils, the fraction of the anti-friction additives further accelerates the wear of DLC when rubbed against steel [10-17]. Sugimoto et al. and Haque et al. both reported that the wears of DLC/steel contact were exceptionally high in MoDTC included lubricant oil [10, 11]. However, the presence of anti-wear additive ZnDTP can dampen the effect of MoDTC thus reduce the wear [11]. The finding is consistent with findings of past studies by Tung et al., which summarized that in the lubrication environment of fully formulated oil, the availability of both MoDTC and ZnDTP can further reduce the friction and wear of DLC film compared to solely MoDTC 
included lubricant oil [12].

For the case of lubrication in glycerol mono-oleate (GMO), the mechanism for steel to steel contact is generally known as the Bowden-Tabor model. The friction modifier component comes from the hydrolysis product of GMO which then generates a long, straight chain of carboxylic acid. However, interestingly, this is contrary to some other studies reported that GMO produces a significant amount of friction reduction when contacted with DLC coating. Instead of forming carboxylic acid during the interaction, GMO contacted with DLC in the shape of ester plus the hydroxyl groups in the molecule enact an important part during the interaction $[18,19]$. Although there were many researches about the reactions between DLC coatings and lubricant additives, only few focused on the effects lubricant additives to the ultra-violet (UV) irradiated DLC coating.

There have been several studies in the literature reporting on the effects of UV irradiation to DLC coatings. Tokoroyama et al. demonstrated that UV light will transforms the uppermost surface of DLC coating into graphite like layer, resulting the light concentration to surpass the bonding energy of carbon to carbon, conjoins the produced dangling bonds, which in turn creates graphite like layer at the uppermost surface of DLC [20, 21]. The finding is consistent with findings of past studies by Zhang et al., which indicated that by conducting UV irradiation to DLC, the process escalates the carbon to carbon and carbon to nitrogen double bonding, and lessening the carbon to hydrogen bonding [22]. The research study by Gadallah et al. also found out that UV irradiation reduces the hydrogen composition and the ratio of $\mathrm{sp} 3$ to $\mathrm{sp} 2$ hybridization consequently produces a long graphene layers on the irradiated DLC coatings. They also discovered that graphite fibres forms on the processed DLC coatings [23]. In addition, according Ji et al., UV irradiation is able to lessen the cross-connection of the carbon affinity, and as a result reduces the friction and wear properties [24]. Again, it appears from the aforementioned investigations that numerous investigations have been conducted on the effects of UV irradiation to DLC coatings. Nonetheless, no attempt was made to investigate the effects lubricant additives to the ultraviolet (UV) irradiated DLC coating. In this investigation, UV irradiation process has been done to hydrogenated amorphous carbon (a-C:H), and their characteristics in terms of friction and tribofilm formation have been studied when lubricated by four types of additives added lubricant oil.

\section{Materials and tests method}

2.1 Hydrogenated DLC and lubricant additives

The a-C:H coating used in this study has $16 \%$ hydrogen content and was formed by a plasma enhanced chemical vapor (PECVD) method on the Si (100) substrate by about $1.8 \mu \mathrm{m}$. The surface roughness had a center line average roughness $R_{a}$ of about $8.2 \mathrm{~nm}$ and a maximum height roughness $R_{y}$ of about 33.6 $\mathrm{nm}$.

Four types of oil used in this study which is anti-wear ZnDTP included base oil, ZnDTP and anti-friction MoDTC included base oil, ZnDTP and anti-friction GMO included base oil and lastly unadulterated base oil. From this point onwards, these 4 types of oil will be referred as only ZnDTP, ZnDTP plus MoDTC, ZnDTP plus GMO and Base.

2.2 UV irradiation and friction tester equipment

In this study, BioLink (Cosmo Bio, BLX-312) was used as a light source for generating ultraviolet rays. One type of discharge tubes (CST-8A) with spectral peaks of wavelengths $254 \mathrm{~nm}$ was used. The maximum UV irradiation energy was 99.99 Jules and the irradiation range was $260 \mathrm{~mm} \times 300 \mathrm{~mm}$. The atmosphere in the UV irradiation box was atmospheric air and the ambient temperature was room temperature.

Figure 1 shows a schematic diagram of the ball-on-disk friction test apparatus used in this research for the friction test under four types of lubrication. In the friction test, the load was $1.0 \mathrm{~N}$ corresponding to maximum initial Hertzian contact pressures of $455 \mathrm{MPa}$, the sliding speed of the two opposing surfaces was $6.28 \times 10^{-2} \mathrm{~m} / \mathrm{s}(200 \mathrm{rpm})$, and the atmosphere temperature was at room temperature. The atmosphere temperature at $24^{\circ} \mathrm{C}$ was purposely picked to create the hardest environment for the tribofilm to be produced on the sliding surfaces which then allowing for significant differences to be seen between the as-deposited and UV irradiated DLC. The tests were then redone again at least 3 times for confirmation and reproducibility of outcomes. Before and after the friction tests, SUJ2 balls and the a-C:H coating disks were cleaned by acetone for fifteen minutes. The above mentioned experimental conditions for the ball-on-disk friction test were then summarized in Table 1.

\subsection{DLC surface and tribofilm analysis equipment}

In this research, atomic force microscope (AFM) was used to measure the DLC coatings surface before and after the ultraviolet irradiation. For the indentation hardness test, nanoindentation hardness tester ENT-2100 manufactured by Elionix was used. To approximate the penetration depth of UV into the

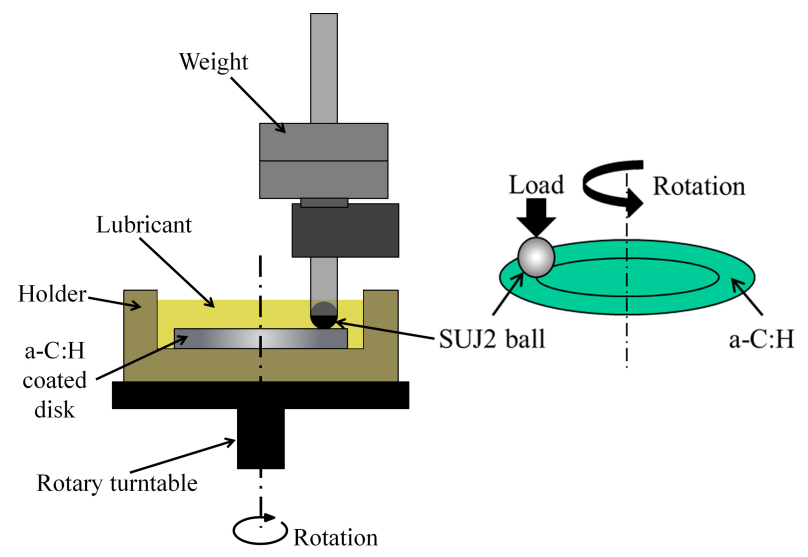

Fig. 1 Schematics of ball-on-disk friction equipment

Table 1 Ball-on-disk friction test experimental conditions

\begin{tabular}{|c|c|}
\hline Experimental conditions & \\
\hline Roller & SUJ2 \\
\hline Disk & a-C:H on $\mathrm{Si}(100)$ \\
\hline Lubricants & $\begin{array}{c}\text { Base } \\
\text { ZnDTP } \\
\text { ZnDTP + MoDTC } \\
\text { ZnDTP + GMO }\end{array}$ \\
\hline Load, $\mathrm{N}$ & 1 \\
\hline $\begin{array}{l}\text { Max. initial Hertzian } \\
\text { contact pressure, MPa }\end{array}$ & 455 \\
\hline Temperature, ${ }^{\circ} \mathrm{C}$ & 24 \\
\hline Rotation speed, rpm & 200 \\
\hline Sliding speed, $\mathrm{m} / \mathrm{s}$ & $6.28 \times 10^{-2}$ \\
\hline Duration, min & 100 \\
\hline
\end{tabular}


$\mathrm{a}-\mathrm{C}: \mathrm{H}$, the coefficient of extinction and refractive index were calculated by utilizing ellipsometery (MART-102). Tribofilm formed on both DLC disks and mating material SUJ2 balls were studied using non-contact, three-dimensional, scanning white light interferometry (Zygo, Newview) and finally tribofilm element study was done by utilizing the energy dispersive X-ray spectroscopy (EDS) to analyze chemical composition of rubbed surfaces.

\section{Results and discussions}

\subsection{Friction coefficient}

To look on the effect of initial running in process to asdeposited and UV irradiated a-C:H disks, Fig. 2 (a) and (b) which focused on the cycles from 0 to 2000 were illustrated and the overall friction coefficients as a function of sliding cycles for SUJ2 balls contacted against as-deposited and UV irradiated a-C:H DLC in four types of additives added lubricant oils are shown in Fig. 3 (a) and (b). The UV irradiated a-C:H in ZnDTP oil showed the lowest friction coefficient, while as-deposited $\mathrm{a}-\mathrm{C}: \mathrm{H}$ showed the highest friction coefficient. For the case of friction test in Base oil, both as-deposited and UV irradiated $\mathrm{a}-\mathrm{C}: \mathrm{H}$ showed a gradual reduction of friction with sliding cycles that exhibited a reduction from initially 0.12 to 0.09 at the end of friction test and from initially 0.12 to finally at 0.08 for each as-deposited and UV irradiated a-C:H respectively. For the case of friction test in $\mathrm{ZnDTP}$ oil, the running in period for both
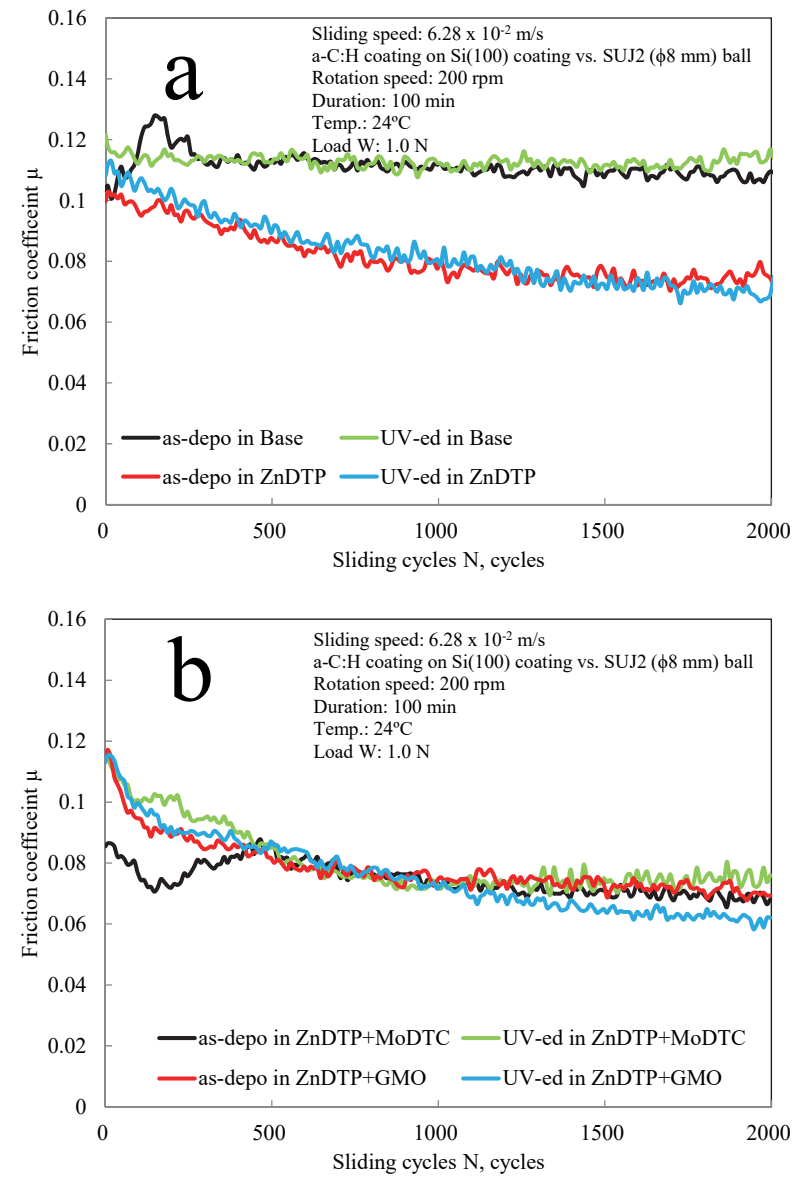

Fig. 2 Friction coefficient of as-deposited and UV irradiated a-C:H coating (a) in Base and ZnDTP oils (b) ZnDTP+MoDTC and $\mathrm{ZnDTP}+\mathrm{GMO}$ oils from 0 to 2000 cycles as-deposited and UV irradiated was longer compared to the previous result in Base oil, which the steady state value gained at somewhere around 2000 cycles. The friction coefficient of asdeposited a-C:H gradually decreased from 0.11 to 0.055 , and 0.11 to 0.04 reduction for $\mathrm{UV}$ irradiated a-C:H.

For the condition of lubrication in ZnDTP+MoDTC oil, friction coefficient of as-deposited a-C:H dropped from initially 0.09 to 0.07 at 500 cycles but bounced back to 0.09 at 1000 cycles then gradually reducing and remained almost constant at 0.06 . However, at 12000 cycles, the friction coefficient increased back to around 0.09 until the end of friction test. This increment of friction coefficient at 12000 cycles might possibly be due to the increasing wear of the a-C:H disk became too high thus increased the friction coefficient. The effect of this increasing friction coefficient later can be seen on the wear track of as-deposited $\mathrm{a}-\mathrm{C}: \mathrm{H}$ disk surface where obvious consistent wear line can be observed along the wear track. However, the same effect had not occurred for the case of UV irradiated a-C:H disk. Although the initial friction coefficient was quite high at 0.115 , the value rapidly reduced to 0.07 at 1000 cycles and remained almost constant until the end of friction test. It can be suggested that, UV irradiation process can lessen the effect of wear acceleration by MoDTC when being lubricated by ZnDTP+MoDTC oil as per reported by previous researchers [10-17].

Lastly, for the lubrication condition of ZnDTP+GMO oil, the running in phase of UV irradiated a-C:H was longer than asdeposited a-C:H. Both type of DLCs started the friction test with
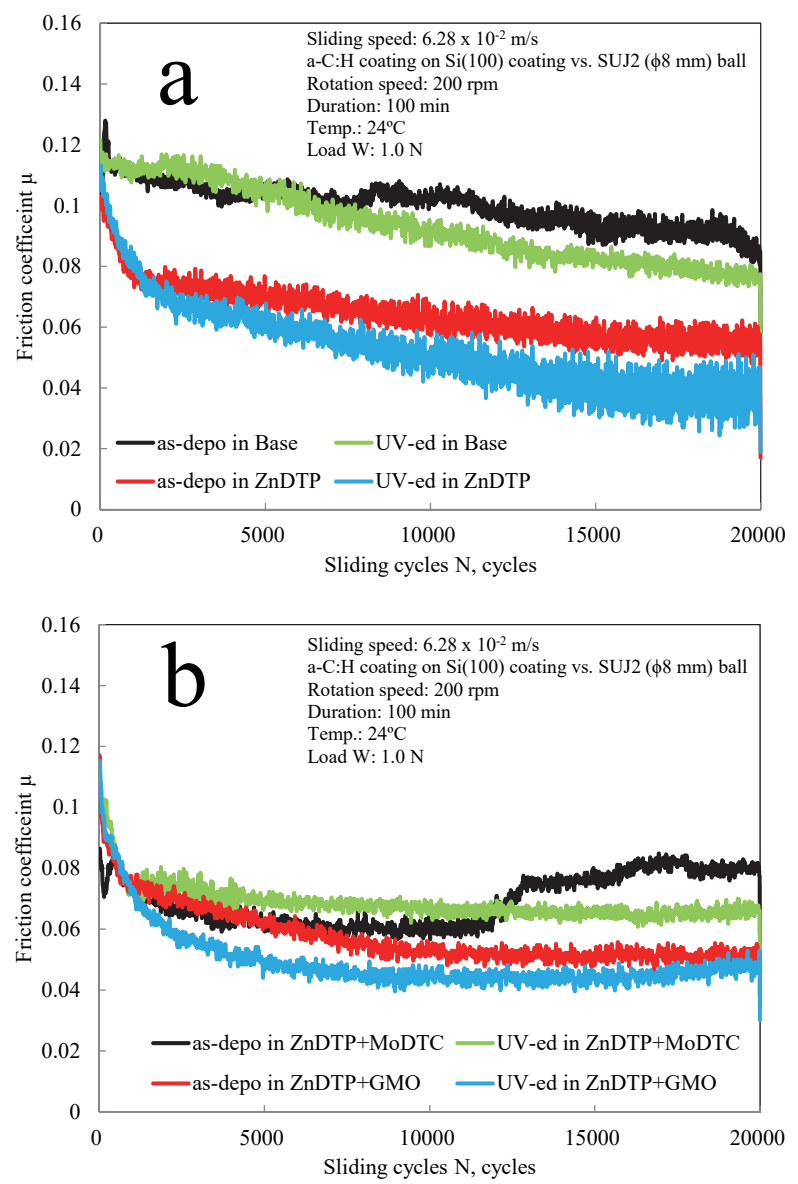

Fig. 3 Friction coefficient of as-deposited and UV irradiated a-C:H coating (a) in Base and ZnDTP oils (b) ZnDTP+MoDTC and $\mathrm{ZnDTP}+\mathrm{GMO}$ oils for overall cycles 
friction coefficient of 0.12 . For as-deposited a-C:H, the value reduced swiftly to 0.075 at 1000 cycles, then gradually reduced to 0.05 at 8000 cycles and stayed almost steady from that point onwards until the end of the friction test, whereas in the UV irradiated a-C:H, the friction coefficient reduced to 0.06 at 2000 cycles, then slowly reduced and stayed at 0.045 at 8000 cycles for the rest of friction test.

To compare which one of lubricant oil gives the lowest and the highest friction coefficient, the results of steady state friction coefficient in the last 5000 cycles of friction test are plotted and charted into a bar graph as shown in Fig. 4. From the result, it can be observed that for the as-deposited a-C:H, the highest friction coefficient was in Base oil, followed by in ZnDTP+MoDTC oil, then in ZnDTP oil and the lowest friction coefficient was in $\mathrm{ZnDTP}+\mathrm{GMO}$ oil. UV irradiated a-C:H showed the first and second highest friction coefficients were in Base and in ZnDTP+MoDTC respectively which was the same like as-deposited a-C:H, but the lowest was in ZnDTP oil instead of in ZnDTP+GMO oil. In each type of lubricant oil, UV irradiated a-C:H showed lower friction coefficient than the asdeposited a-C:H with reduction from 0.091 to 0.080 in Base oil, 0.056 to 0.038 in ZnDTP oil, 0.080 to 0.065 in ZnDTP+MoDTC oil and 0.051 to 0.046 in $\mathrm{ZnDTP}+\mathrm{GMO}$ oil.

\subsection{Wear rates}

The wear rates of SUJ2 balls rubbed against as-deposited and UV irradiated a-C:H and wear rates of as-deposited and UV irradiated a-C:H disks are shown in Figs. 5 and 6 respectively. Wear rates of SUJ2 balls in Base, ZnDTP and ZnDTP+GMO oils shows relatively high wear than in $\mathrm{ZnDTP}+\mathrm{MoDTC}$ oil. Wear rates of UV irradiated a-C:H disks in Base and ZnDTP+MoDTC

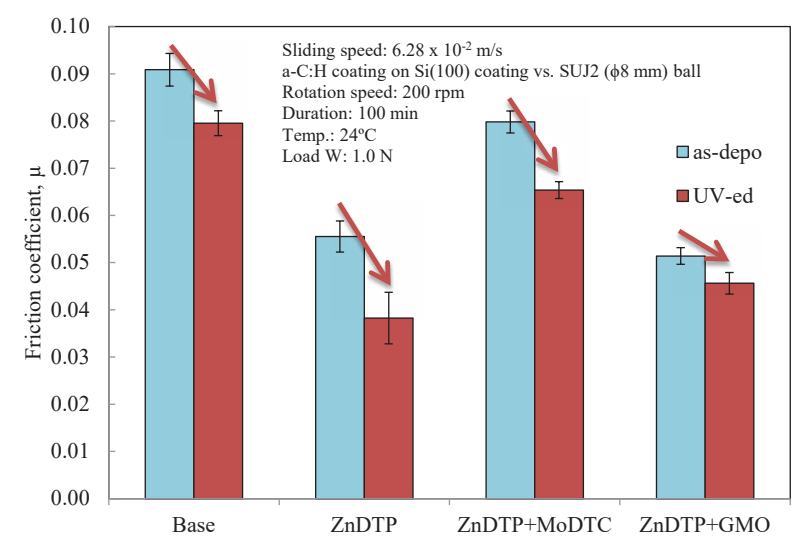

Fig. 4 Average friction coefficient of as-deposited and UV irradiated a-C:H coating in four different types of oil

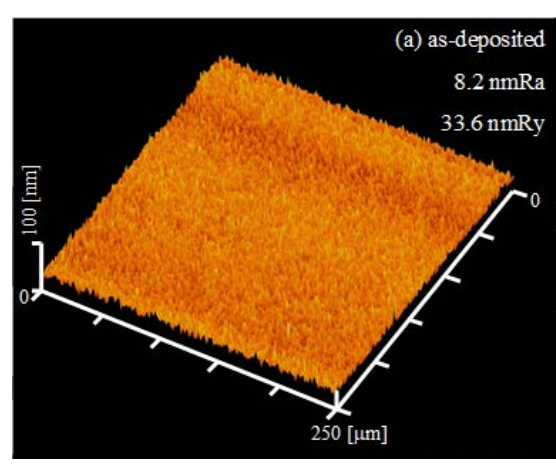

Fig. 7 AFM images of as-deposited and UV irradiated a-C:H coating

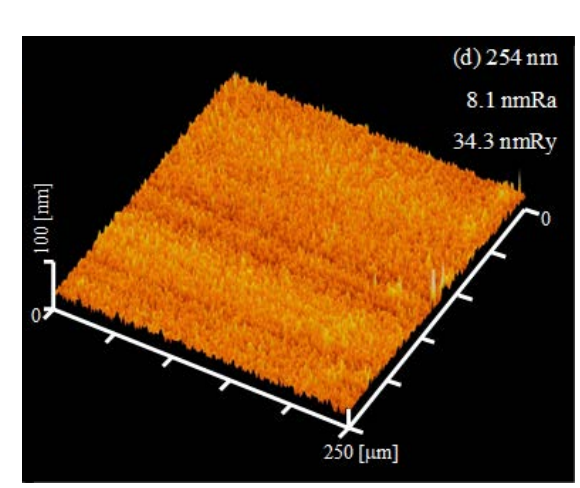

demonstrates significant reduction compared to the asdeposited a-C:H disks. The combination of UV irradiated a-C:H in $\mathrm{ZnDTP}+\mathrm{MoDTC}$ able to accommodate an environment that can provide the lowest wear for both SUJ2 ball and a-C:H disk compared to the other combinations. ZnDTP and ZnDTP+GMO on the other hand capable to administer lower friction coefficient compared to the other two types of oils as can be seen in Fig. 4, and also provide lower wear rate on both as-deposited and UV irradiated a-C:H disks. However, the wear rates of SUJ2 balls are comparatively higher than in $\mathrm{ZnDTP}+\mathrm{MoDTC}$.

\subsection{Surface roughness and hardness}

Figure 7 shows the AFM image of the a-C:H coating surface irradiated with ultraviolet light for 60 minutes. The center-

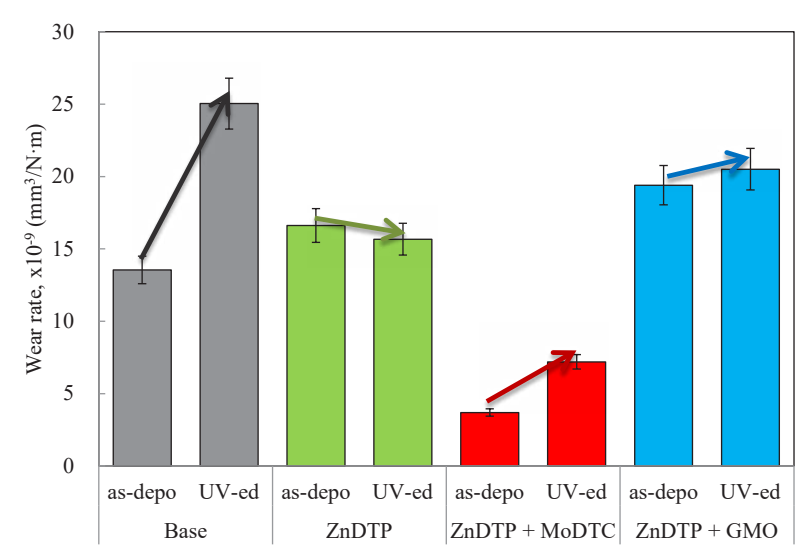

Fig. 5 Wear rates of SUJ2 balls rubbed against as-deposited and UV irradiated a-C:H disks in four types of lubricant oil

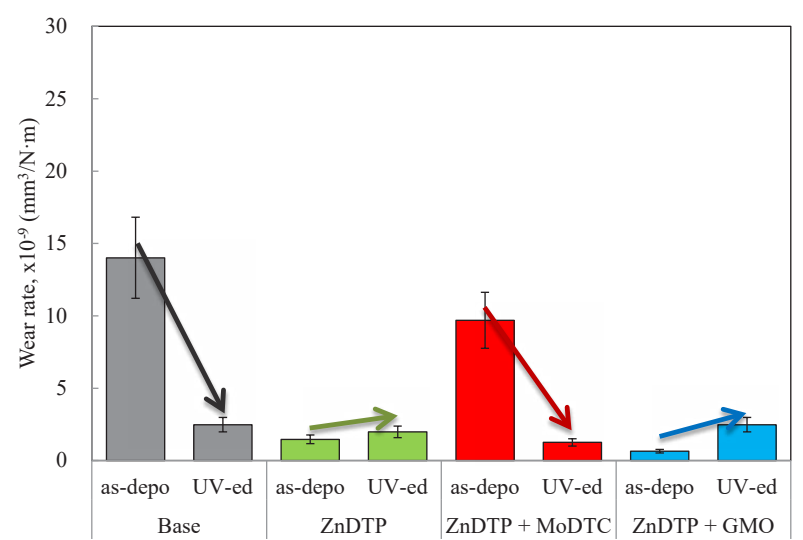

Fig. 6 Wear rates of as-deposited and UV irradiated a-C:H disks rubbed against SUJ2 balls in four types of lubricant oil 
Table 2 The hardness and Young's modulus of as-deposited and UV irradiated a-C:H coating

\begin{tabular}{lcc}
\hline Coating type & \multicolumn{2}{c}{ a-C:H } \\
\hline UV wavelength & As-deposited & $254 \mathrm{~nm}$ \\
\hline Hardness $H, \mathrm{GPa}$ & 16.7 & 16 \\
\hline Hardness standard deviation, GPa & 1.0 & 0.7 \\
\hline Young's modulus E, GPa & 15.2 & 15.2 \\
\hline Young's modulus standard deviation, GPa & 4.7 & 1.6 \\
\hline
\end{tabular}

line average roughness $\left(R_{a}\right)$ of the as-deposited a-C:H coating was about $8.2 \mathrm{~nm}$ and the maximum height roughness $\left(R_{y}\right)$ was about $33.6 \mathrm{~nm}$. The surface roughness of the a-C:H coating irradiated with ultraviolet rays of $254 \mathrm{~nm}$ for 60 minutes was about $8.1 \mathrm{~nm}$ in the center-line average roughness $\left(R_{a}\right)$, and about $34.3 \mathrm{~nm}$ in the maximum height roughness $\left(R_{y}\right)$.

In order to clarify the change in the hardness of the a-C:H coating by ultraviolet irradiation, the a-C:H coating irradiated with ultraviolet rays of $254 \mathrm{~nm}$ wavelength for 60 minutes was subjected to indentation hardness test by a micro indentation hardness tester. The indentation load was set to $49 \mu \mathrm{N}$ to confirm the change in the hardness of only the topmost surface of the a-C:H coating. Table 2 shows the hardness and Young's modulus of the topmost surfaces of the as-deposited and $\mathrm{UV}$ irradiated a-C:H coating. The findings suggest that UV irradiation gave no significant change to a-C:H coating in terms of roughness and hardness.

\subsection{UV irradiation penetration depth}

Previous study done by Tokoroyama et al. found that the UV irradiation time of $60,120,180$ and 240 minutes do not shows significant changes among them and they also clarified that the effect of UV irradiation by calculating penetration depth of three types of UV light wavelength into a-C:H coating by utilizing ellipsometery. The penetration depth $d_{p}$ of light is expressed by the following equation

$$
d_{p}=1 / \alpha
$$

In this formula, $\alpha$ represents the absorption coefficient of the material and is obtained by the following equation

$$
\alpha=\frac{4 \pi k}{\lambda}
$$

Here, $\lambda$ is the wavelength of light, and $k$ is the extinction coefficient. Since ultraviolet wavelengths are 365, 312 and 254 $\mathrm{nm}$, it is possible to estimate the penetration depth of ultraviolet rays by clarifying the extinction coefficient of the a-C:H coating. As a result of the ellipsometry measurement, extinction coefficients of the a-C:H coating are about 2.19. Ultraviolet penetration depths to the a-C:H coating at each wavelength were calculated by using the extinction coefficients of each and the previous two equations, and are shown in Table 3. In the a-C:H coating, the penetration depth of over $9 \mathrm{~nm}$ at any wavelength was calculated at any wavelength [20].

3.5 Ball and disk wear track surface profile observation

Figure 8 shows the optical microscope images of SUJ2 balls contacted with as-deposited and UV irradiated a-C:H disks. From the images, it can be observed that SUJ2 balls contacted with UV irradiated a-C:H showed darker traces compared to the as deposited a-C:H contacted SUJ2 balls. These traces found on the SUJ2 ball surfaces are likely to be the tribofilm as a result of the rubbing between the two surfaces. And since the traces were darker on the UV irradiated counter material surfaces, it can be concluded that a-C:H disks exposed to UV light are capable of producing thicker tribofilm compared with a-C:H disks without exposure to UV light. To support this claim, non-contact, three-

Table 3 The ultraviolet penetration depth to the a-C:H coating and the a-C film at each wavelength

\begin{tabular}{cc}
\hline \multirow{2}{*}{ Wavelength } & Penetration depth $d_{p}, \mathrm{~nm}$ \\
\cline { 2 - 2 } & $\mathrm{a}-\mathrm{C}: \mathrm{H}$ \\
\hline $365 \mathrm{~nm}$ & 13.3 \\
\hline $312 \mathrm{~nm}$ & 11.3 \\
\hline $254 \mathrm{~nm}$ & 9.2 \\
\hline
\end{tabular}
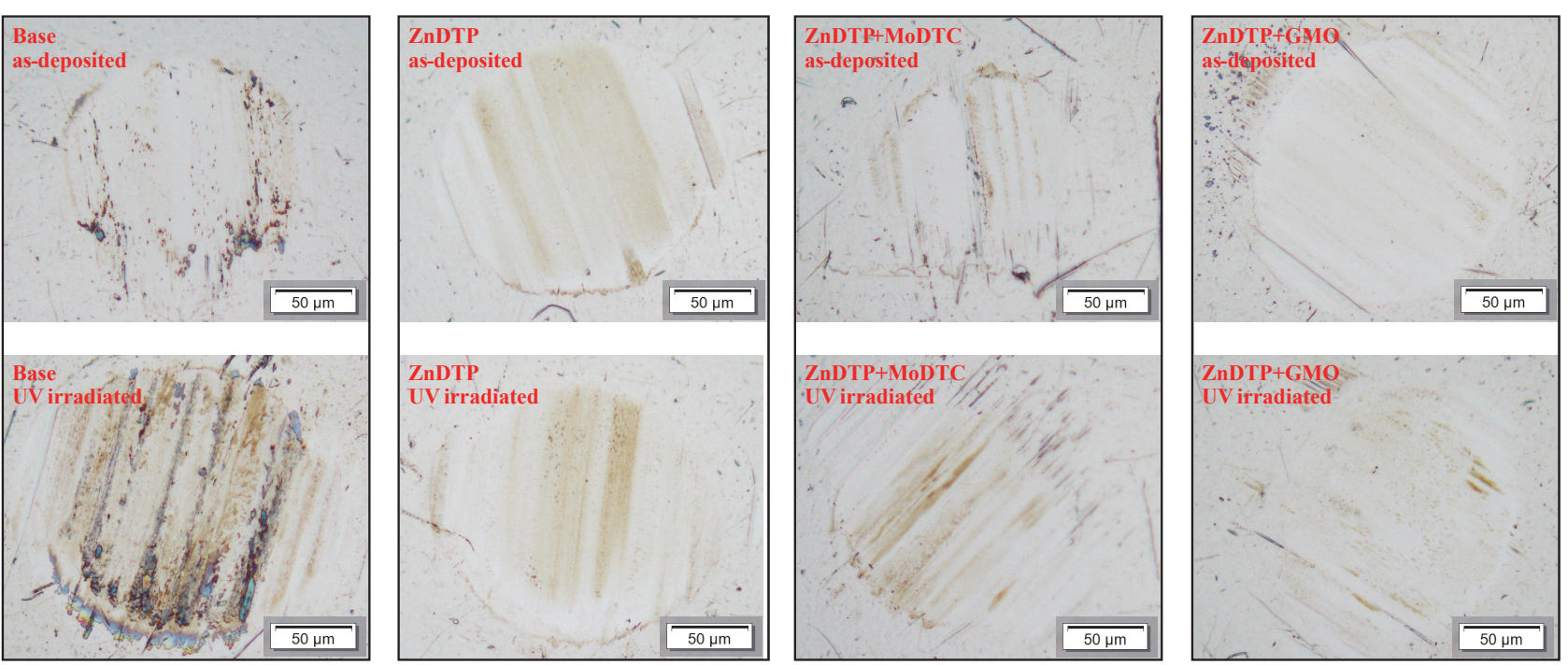

Fig. 8 Optical images of SUJ2 balls after friction test lubricated with (a) Base, (b) ZnDTP (c) ZnDTP+MoDTC and (d) ZnDTP+GMO 

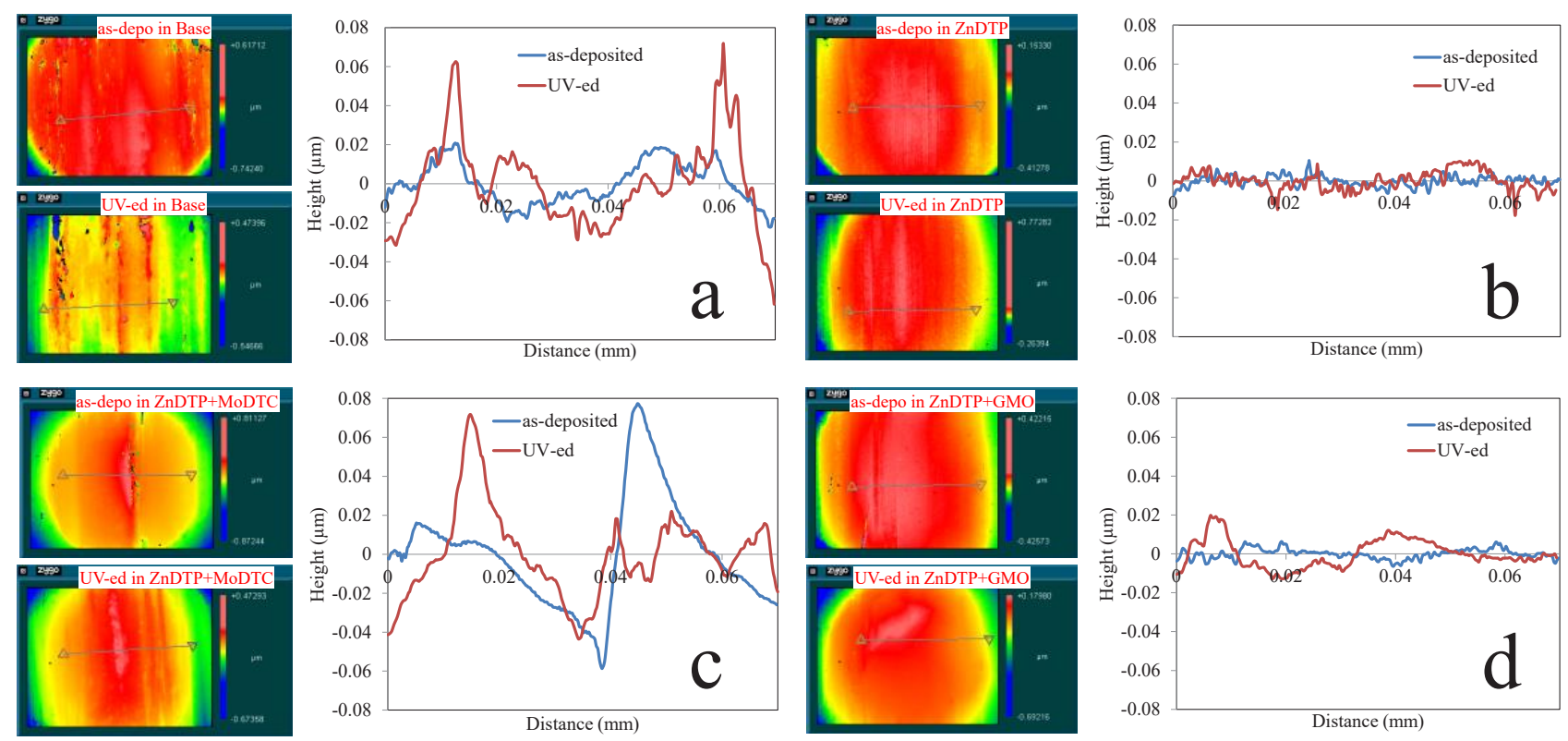

Fig. 9 Zygo images and surface profiles of SUJ2 balls after friction test lubricated with (a) Base, (b) ZnDTP (c) ZnDTP+MoDTC and (d) $\mathrm{ZnDTP}+\mathrm{GMO}$

dimensional, scanning white light interferometry, Zygo was utilized to acquire the surface profile of tribofilm formed on the SUJ2 balls.

Figure 9 (a)-(d) shows the Zygo images and surface profile graphs of as-deposited and UV irradiated a-C:H disks mating material SUJ2 ball in Base, ZnDTP, ZnDTP+MoDTC and $\mathrm{ZnDTP}+\mathrm{GMO}$ oils respectively. The results then compiled and converted into bar graph shown in Fig. 10, where the UV irradiated a-C:H disks mating material exhibited higher tribofilm height than the as-deposited disks mating material with an increment from 21 to $72 \mathrm{~nm}$ in Base oil, 10 to 12 $\mathrm{nm}$ in ZnDTP oil, 6 to $20 \mathrm{~nm}$ in ZnDTP+GMO oil, except in ZnDTP+MoDTC oil where the height decrease from 77 to 72 $\mathrm{nm}$. This reduction of tribofilm height can be explained by looking at the results of EDS-SEM on SUJ2 balls in the next section where the amount of Sulphur reduced for the case of lubrication in $\mathrm{ZnDTP}+\mathrm{MoDTC}$ for the UV irradiated a-C:H and the rest type of oils showed increment of oil additives at $\%$ for the UV irradiated a-C:H. These findings suggest that the higher the value of surface profile height, the thicker the thickness of tribofilm attached on the SUJ2 balls. The result also revealed that UV irradiated a-C:H disks made the thickness of the tribofilm higher on SUJ2 balls than the as-deposited a-C:H disks.

The analysis of a-C:H disks wear track was done next by utilizing Zygo images and surface profile graphs of asdeposited and UV irradiated a-C:H disks in the four different types of oil and the results are shown in Fig. 11 (a)-(d). The results then compiled and converted into bar graph shown in Fig. 12. Compared to the results of SUJ2 balls, the tribofilm height formed of a-C:H disks were much more lower compared to the ones formed on the SUJ2 balls. In general, UV irradiated a-C:H disks exhibited slightly higher tribofilm height than the as-deposited a-C:H disks with an increment from 2.2 to $2.5 \mathrm{~nm}$ in ZnDTP oil and 2.2 to $3.6 \mathrm{~nm}$ in $\mathrm{ZnDTP}+\mathrm{GMO}$ oil. However, for the case in Base and $\mathrm{ZnDTP}+\mathrm{MoDTC}$, the tribofilm height reduced slightly from 5.0 to 3.6 and 6.5 to $4.9 \mathrm{~nm}$ respectively. Except for the case of Base oil, the rest of results show the same trend as SUJ2 balls where the UV irradiated disks formed thicker tribofilm than as-deposited disks. And the reduction

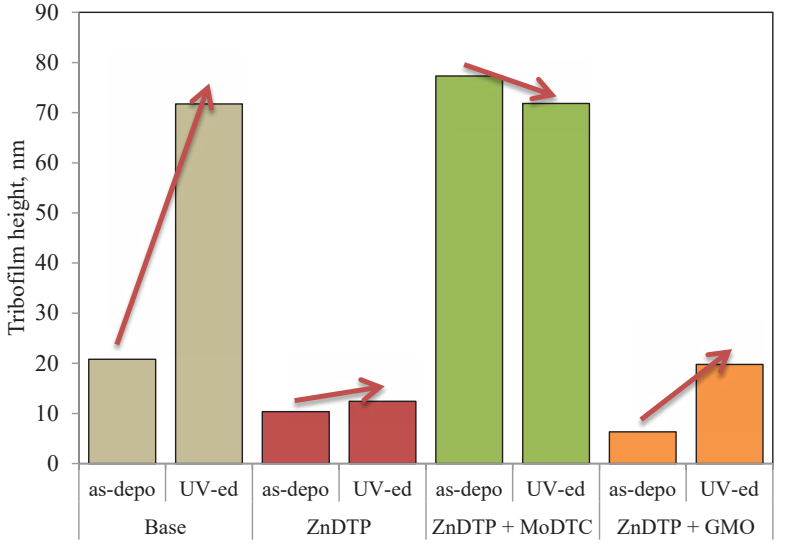

Fig. 10 Tribofilm height on SUJ2 balls after rubbed against asdeposited and UV irradiated a-C:H disks in four types of lubricant oil

of tribofilm height in ZnDTP+MoDTC for the UV irradiated disks was probably due to the reduction of elements such as Molybdenum and Sulphur attachment that will be explain later on the upcoming section.

\subsection{Tribofilm element investigation}

To identify which oil additives element attached on both sliding surfaces, an energy dispersive X-ray spectroscopy (EDS) was used to carry out qualitative element analysis for both sliding surfaces. Figures 13 and 14 show the SEM images location area of the EDS scanning for SUJ2 balls and both asdeposited and UV irradiated a-C:H disks after friction tests. Figures 15 and 16 shows the concentration of Carbon element attached on SUJ2 balls and as-deposited and UV irradiated $\mathrm{a}-\mathrm{C}: \mathrm{H}$ disks. The source of this carbon that attached on both sliding surfaces mainly originated from two sources which are carbon derived from lubricant oils and carbon from the wear particles of graphite like layer produced from the UV irradiation process.

Except for the case in Base oil, the attachment of carbon 

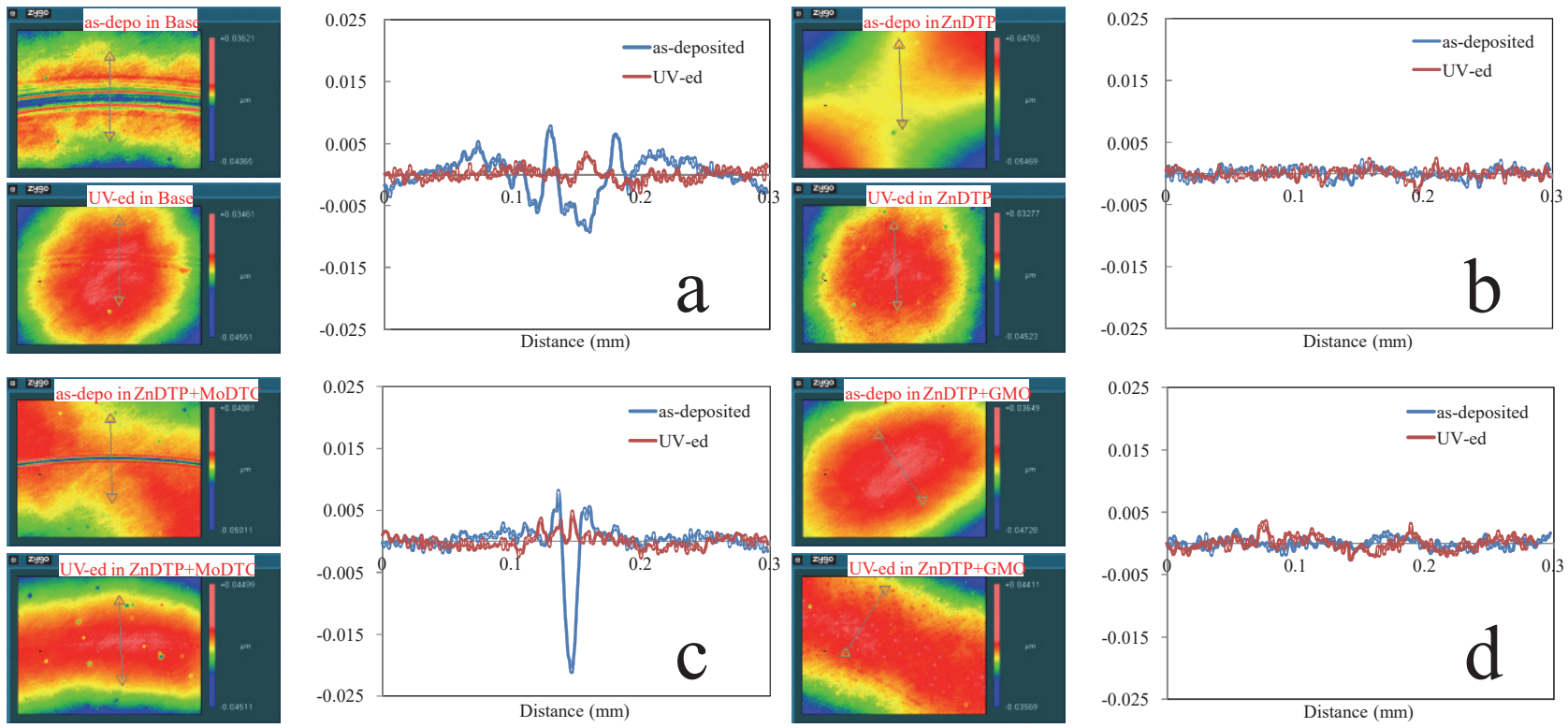

Fig. 11 Zygo images and surface profiles of as-deposited and UV irradiated a-C:H disks after friction test in (a) Base, (b) ZnDTP (c) ZnDTP+MoDTC and (d) ZnDTP+GMO

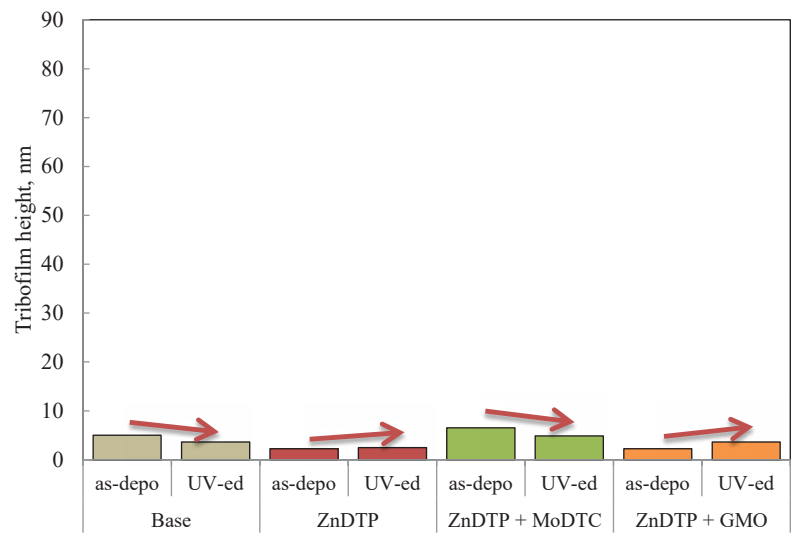

Fig. 12 Tribofilm height on as-deposited and UV irradiated a-C:H disks after rubbed against SUJ2 balls in four types of lubricant oil element on SUJ2 when being rubbed against UV irradiated a-C:H disks was lower than when being rubbed against asdeposited a-C:H disks in ZnDTP, ZnDTP+MoDTC and ZnDTP+GMO lubricant oils. The increment of carbon when rubbed against UV irradiated a-C:H in Base oil, the finding highlights that the wear particles of graphite like layer from a-C:H disk adhered to the SUJ2 ball surface and then accumulates with carbon elements came from Base oil. However, for the other three types of additives added lubricant oils, elements that came from the oil additives such as Zinc, Sulphur, Phosphorus and Molybdenum substitutes some portion of carbon place explaining the logic behind the reduction of carbon attachment on SUJ2 balls when rubbed against UV irradiated a-C:H. Carbon attachment on a-C:H disks however exhibits an increment from as-deposited to UV irradiated a-C:H disks in all type of lubricant oils. The finding is consistent with findings of past studies by Zhang et. al.,
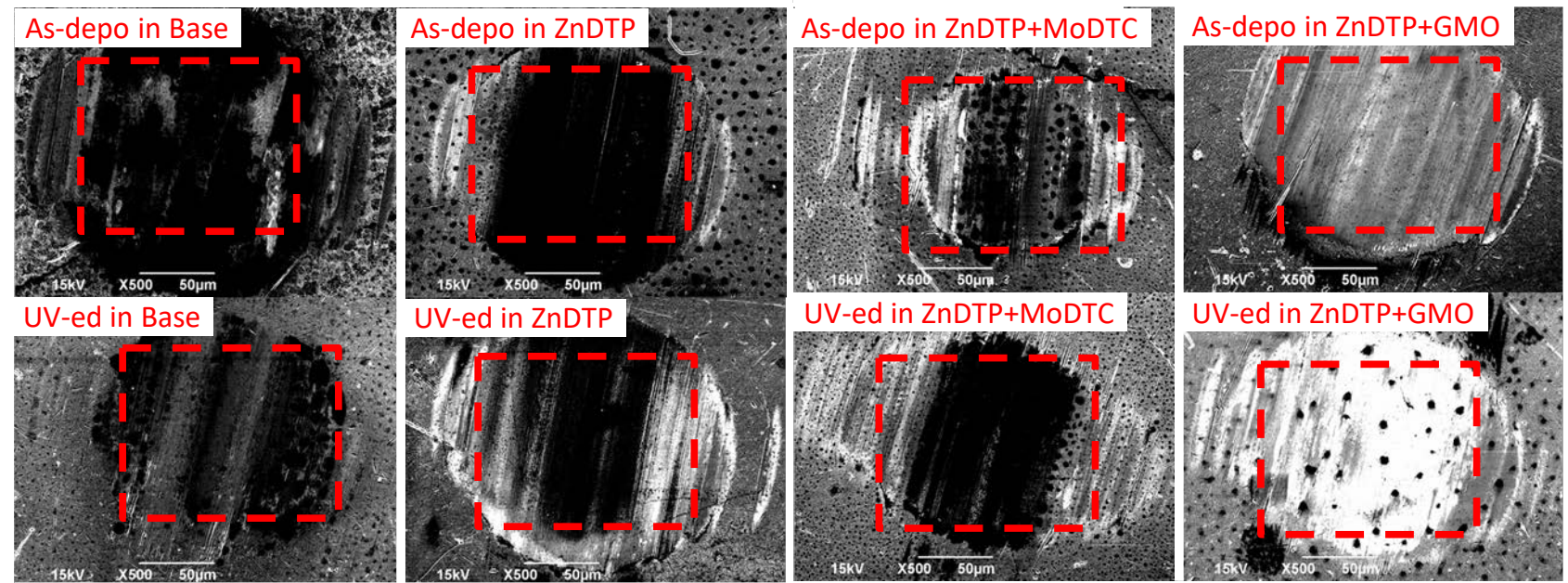

Fig. 13 SEM images location area of the EDS scanning for mating material SUJ2 balls contacted to as-deposited and UV irradiated a-C:H disks in four types of lubricant oil 

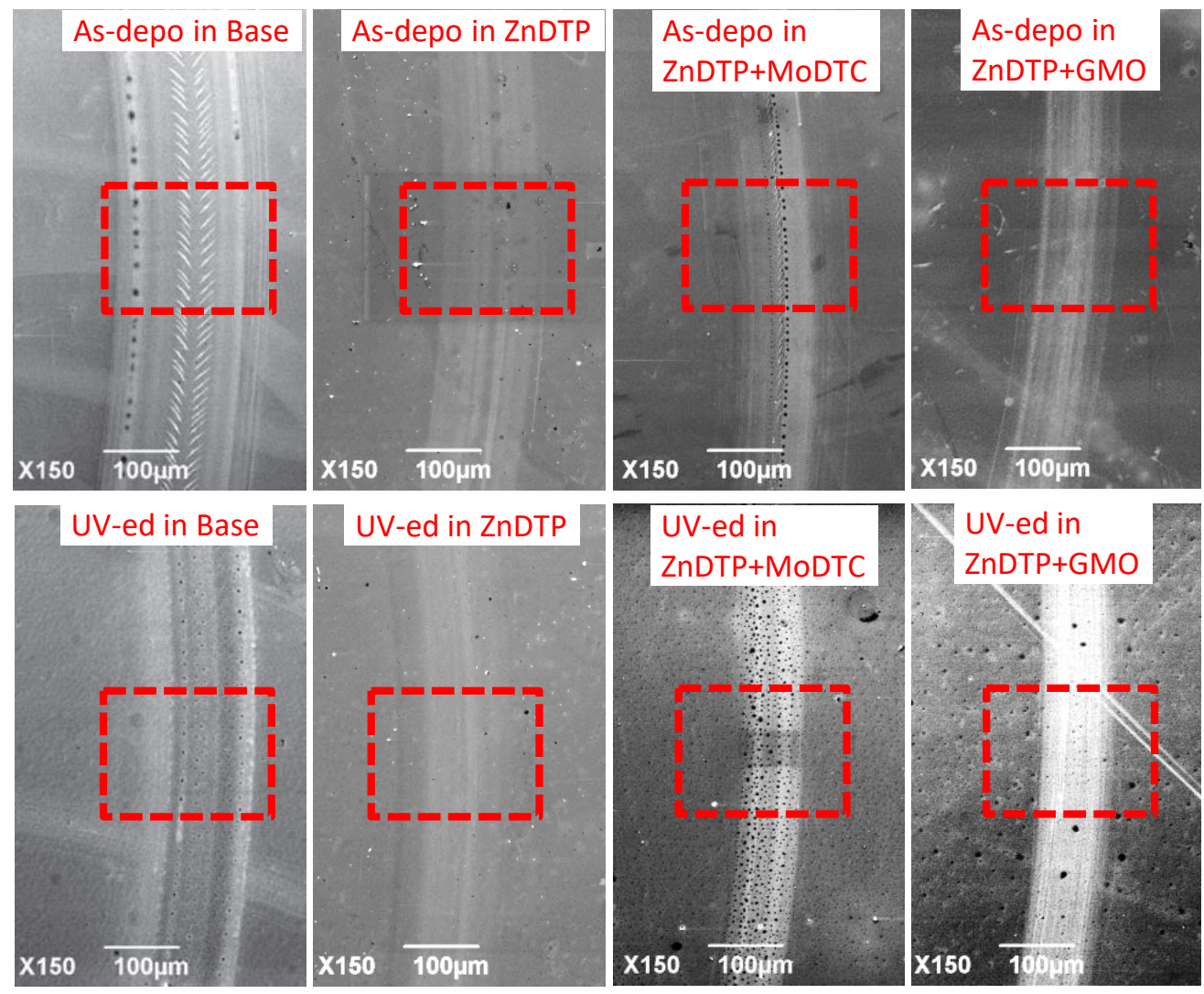

Fig. 14 SEM images location area of the EDS scanning for both as-deposited and UV irradiated a-C:H disks in four types of lubricant oil

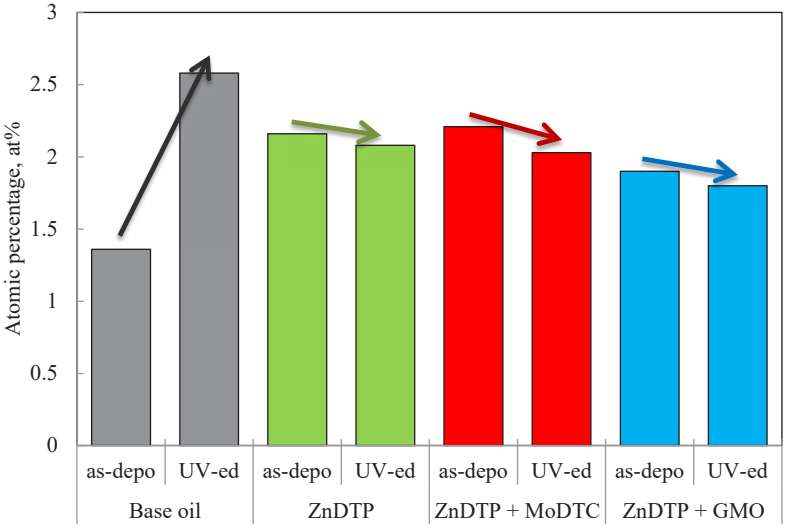

Fig. 15 Carbon element analysis by EDS on SUJ2 balls

which indicated that by conducting UV irradiation to DLC, the process escalates the carbon to carbon and lessening the carbon to hydrogen bonding [22], explaining the higher concentration of carbon at $\%$ on UV irradiated a-C:H disks despite the type of lubricant oils.

Main elements of ZnDTP, MoDTC and GMO lubricant additives which are Phosphorus, Sulphur, Zinc and Molybdenum concentration values then converted into bar graphs as shown in Figs. 17 and 18 to evaluate the effect of UV irradiation to tribofilm and lubricant additives elements attachment on both sliding surfaces. It was clear that there are no lubricants additives element detected on SUJ2 balls lubricated with Base oil, however in ZnDTP lubrication, higher traces of lubricant additives was detected on SUJ2 ball

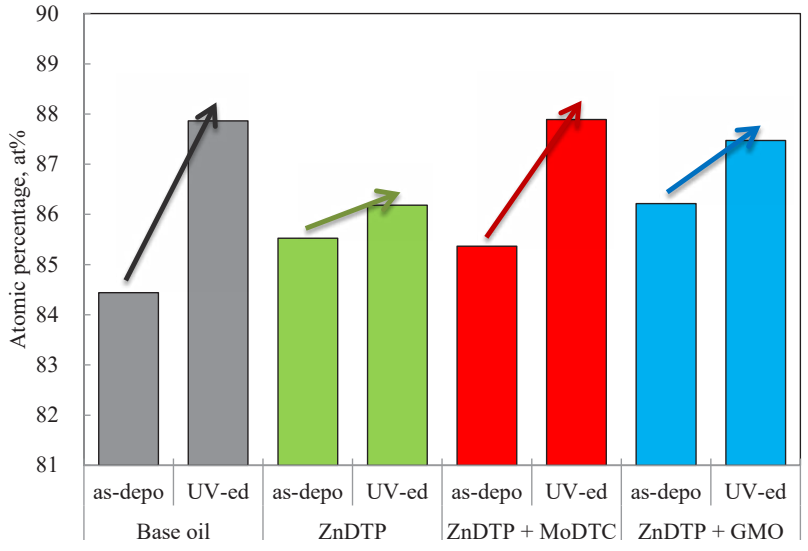

Fig. 16 Carbon element analysis by EDS on as-deposited and UV irradiated a-C:H disks

contacted to UV irradiated a-C:H disks. The same result can be seen in $\mathrm{ZnDTP}+\mathrm{GMO}$ lubrication but for the lubrication in ZnDTP+MoDTC, except for Sulphur that cannot be traced on SUJ2 ball of UV irradiated a-C:H disk. The rest of the elements showed higher atomic percentage compared to the case of as deposited a-C:H disk.

Similar to the result on the SUJ2 ball, no lubricants additives element can be found on both as-deposited and UV irradiated a-C:H disks when lubricated with Base oil either. As same with previous SUJ2 results, UV irradiated a-C:H disks showed higher lubricant additives attachment compared to the asdeposited a-C:H disks. Except for the case of lubrication in $\mathrm{ZnDTP}+\mathrm{MoDTC}$ where the Sulphur and Molybdenum elements 
decreased on UV irradiated a-C:H disk, all the other lubricant additives elements attached more on UV irradiated than asdeposited a-C:H disks. Based on these results, the findings suggest that UV irradiation process has helped to generate thick

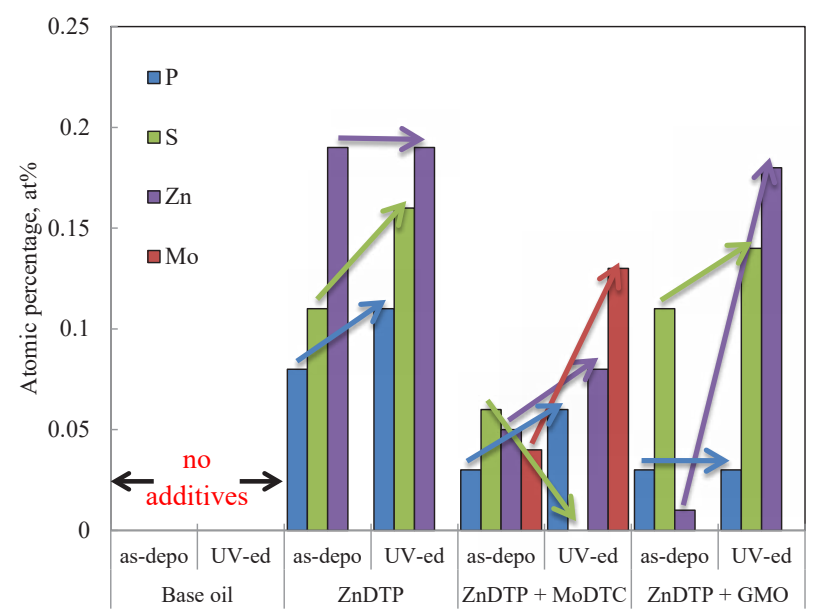

Fig. 17 Lubricant additives element analysis by EDS on SUJ2 balls

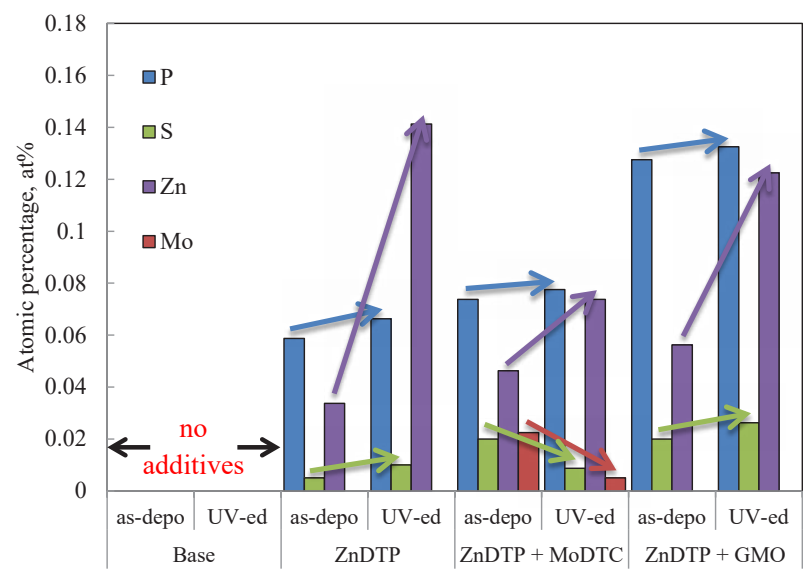

Fig. 18 Lubricant additives element analysis by EDS on asdeposited and UV irradiated a-C:H disks tribofilm on both UV irradiated a-C:H and its counterpart SUJ2 balls. These were made possible by the dangling bonds and thin graphite like layer formed on the topmost surface of a-C:H disk and is consistent with findings of past studies [22-24]. The thin graphite like layer and dangling bonds that produced by the UV irradiation process somehow able to reduce the ability of Molybdenum and Sulphur to attach on the sliding surfaces. Molybdenum and Sulphur both are the main elements contained in MoDTC and as being reported by Sugimoto et al. and Haque et al., the wears of contact between DLC and steel were exceptionally high in MoDTC included lubricant oil [10,11]. Thanks to the the reduction of both element attachment on the sliding surfaces, the wear rate of UV irradiated a-C:H disk was significantly reduced compared to the as-deposited disk.

3.7 Tribofilm formation on SUJ2 balls, as-deposited and UV irradiated a-C:H disk

Based on the entire results before, Figs. 19 and 20 were illustrated to propose on the tribofilm formation phase on asdeposited and UV irradiated a-C:H disk. For the case of contact between SUJ2 ball and as-deposited a-C:H disk, the first image shows the initial contact condition between SUJ2 ball and asdeposited a-C:H disk. At the initial phase of sliding process, tribofilm formed on only on SUJ2 balls and not on a-C:H disk due to its chemically inertness. Along the time of friction test, tribofilm formed on SUJ2 ball was transferred and attached to counter material a-C:H disk. This explains the small traces of lubricant additives element found on as-deposited a-C:H disk and its counter material SUJ2 ball.

Next, for the contact between SUJ2 ball and UV irradiated $\mathrm{a}-\mathrm{C}: \mathrm{H}$ disk, the initial contact during the start-up was actually between SUJ2 ball and graphite like layer formed on the topmost surface of a-C:H disk. Thanks to the graphite like layer and dangling bonds made available by UV irradiation, thin tribofilm then formed on both SUJ2 ball and a-C:H disks. As a result of cyclic process, tribofilm formed on both on SUJ2 ball and a-C:H disk had accumulated and thicker tribofilm comprises of carbon and lubricant additives elements was formed on both SUJ2 ball and UV irradiated a-C:H disk. This justifies the earlier EDS results of higher carbon and lubricant additives elements on found on both SUJ2 ball and UV irradiated a-C:H disk which was consistent with findings of past study by Gadallah et. al. [23].

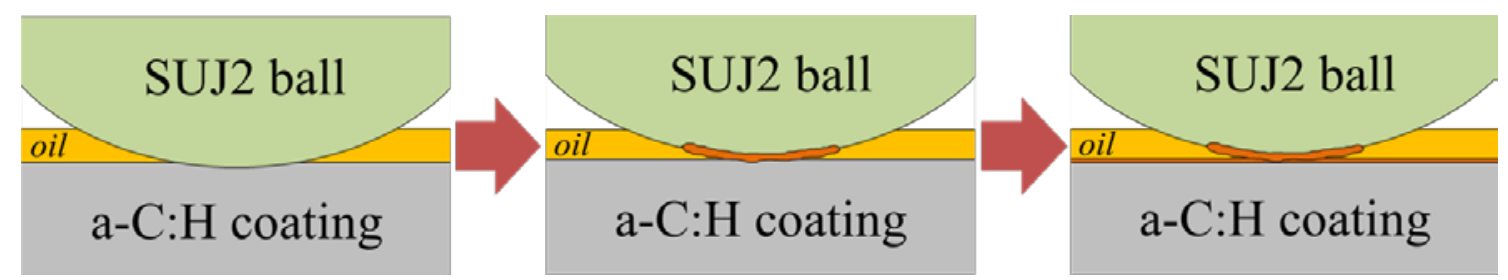

Fig. 19 Tribofilm formation phase on SUJ2 ball and as-deposited a-C:H disk

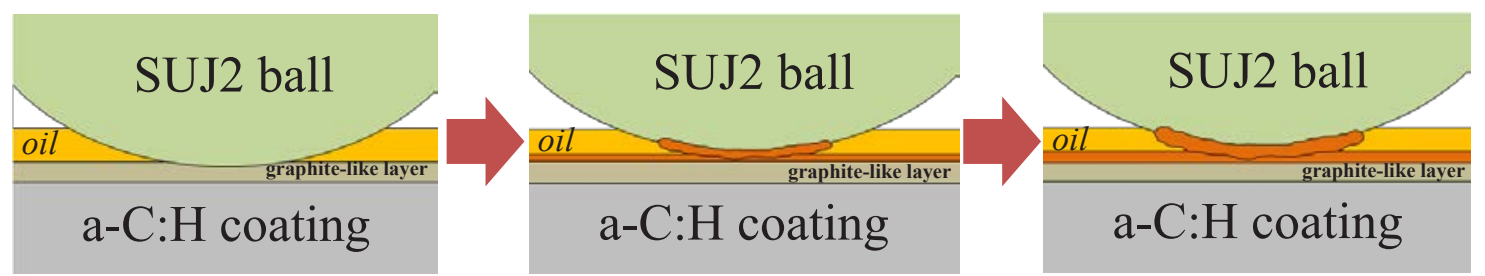

Fig. 20 Tribofilm formation phase on SUJ2 ball and UV irradiated a-C:H disk 


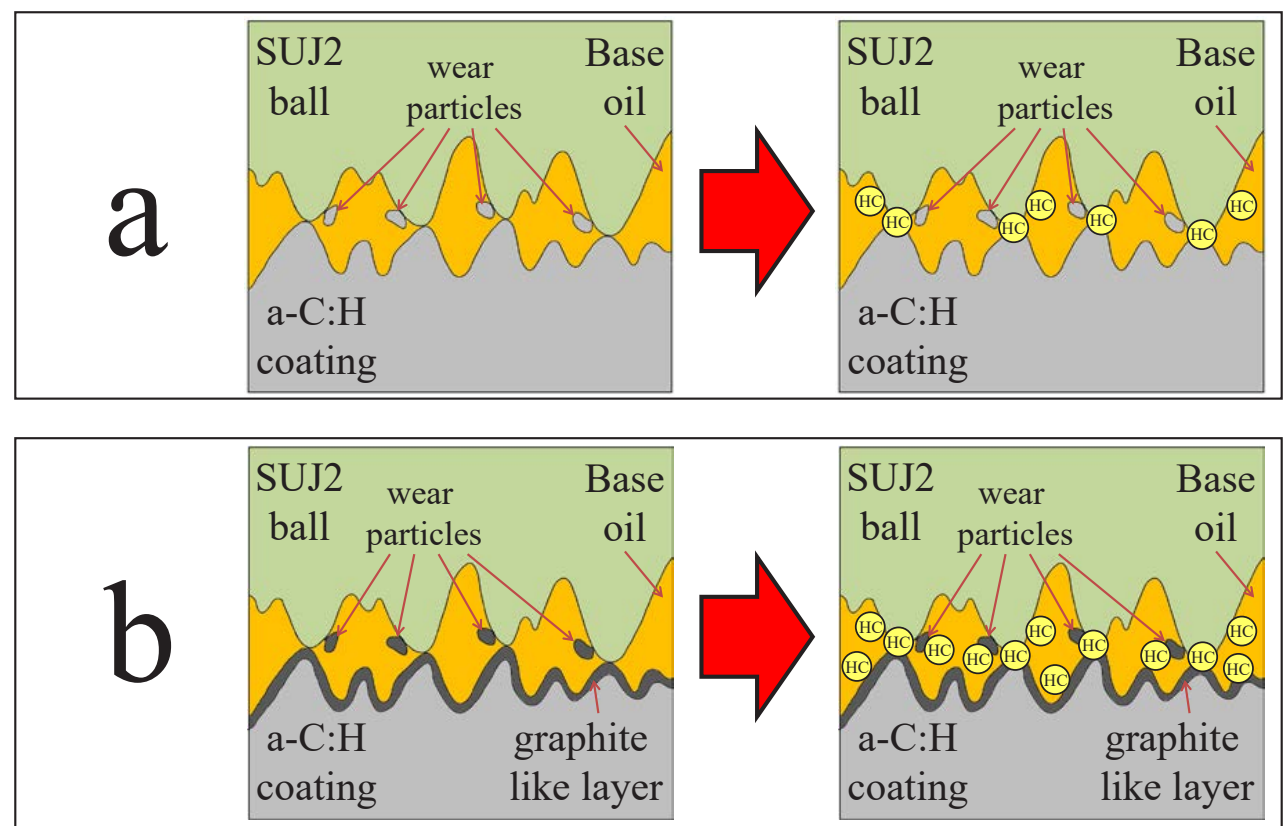

Fig. 21 Tribofilm formation mechanism on SUJ2 ball and (a) as-deposited (b) UV irradiated a-C:H disk in Base oil
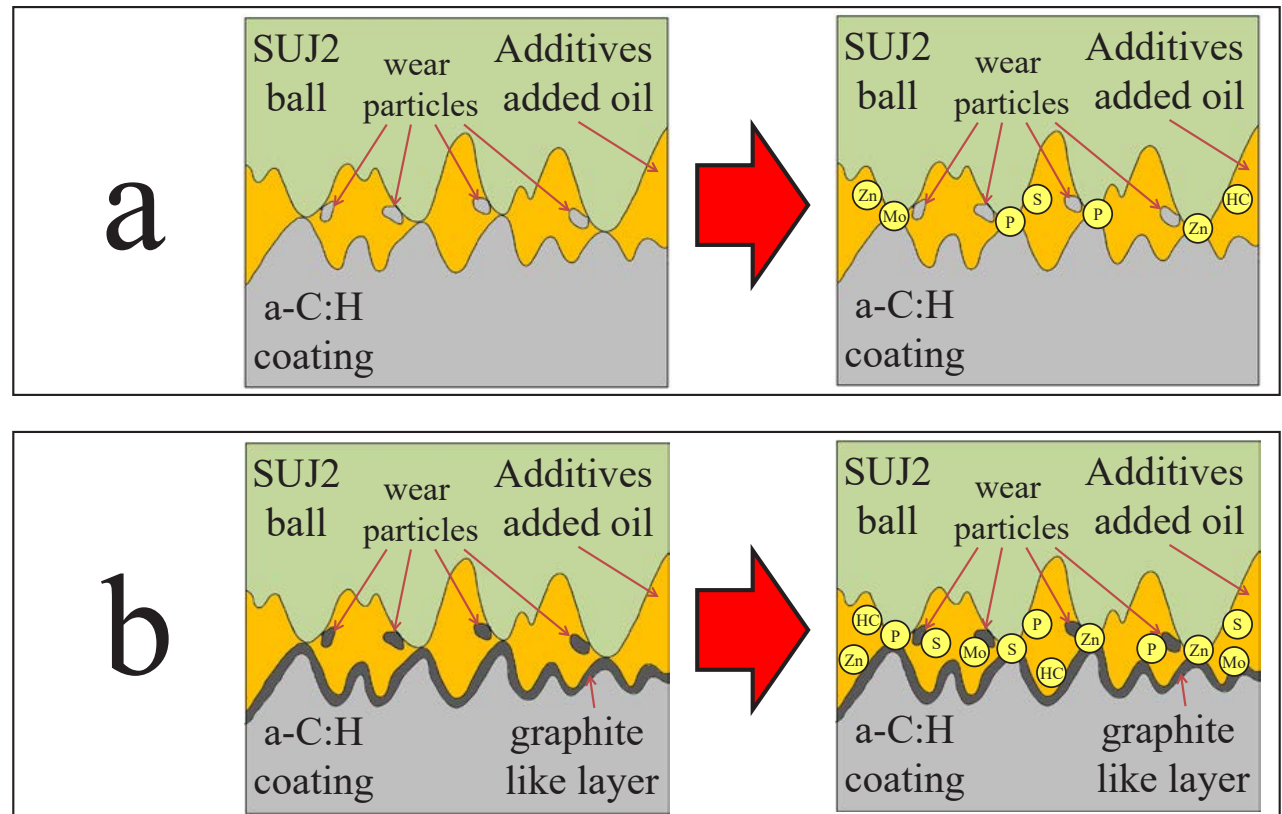

Fig. 22 Tribofilm formation mechanism on SUJ2 ball and (a) as-deposited (b) UV irradiated a-C:H disk in additives added oils

3.8 Base, ZnDTP, ZnDTP+MoDTC and ZnDTP+GMO oils tribofilm formation mechanism on as-deposited and UV irradiated disks

To get better understanding on what exactly are the tribofilm of Base, ZnDTP, ZnDTP+MoDTC and ZnDTP+GMO are made of, Fig. 21 ((a) and (b)) also Fig. 22 ((a) and (b)) was illustrated to explain the mechanism on how the tribofilm can be produced on as-deposited and UV irradiated sliding surfaces in Base and additives added oils (ZnDTP, ZnDTP+MoDTC and $\mathrm{ZnDTP}+\mathrm{GMO}$ ) respectively. For the case in Base, the tribofilm formed on both sliding surfaces can be attributed to the solid derived tribofilm and oil derived tribofilm. At the initial process of friction test in Base for the as-deposited DLC, both surfaces contacted and by the effects of adhesive wear, the worn particles of a-C:H DLC asperities attached and adhered on the SUJ2 ball surface. These wear particles then became the solid derived tribofilm originated from the DLC. Then, due to no additives added inside the Base, the oil derived tribofilm which was mainly the hydrocarbon originated from Base attached to the surface of SUJ2 ball. Possibly, no oil derived tribofilm attached to the DLC disk initially due to its chemical inertness properties. But, as a result of repeated process, the tribofilm formed on the SUJ2 ball accumulated and then transferred to the DLC surface which explain the small traces of lubricant additives elements found on the as-deposited a-C:H disk.

However, for the case of friction test for the UV irradiated DLC in Base, the wear particles that wear during the sliding process was actually the DLC graphite like layer that contains 
dangling bonds. These wear particles then attached to the SUJ ball making both disk and ball surfaces available for the oil elements to attach to. Hydrocarbon from the oil then attached to three surfaces which are the ball surface, graphite like layer wear particles surface and graphite like layer on UV irradiated disk surface thus producing thick tribofilm between the ball and disk that further reduce the friction coefficient.

Next, the mechanism of tribofilm formation on as-deposited and UV irradiated sliding surfaces in additives added oils. The overall process of tribofilm attachment is quite similar with the Base. The difference is, instead of only hydrocarbon, elements such as Zinc, Sulphur, Phosphorus and Molybdenum were also detected attached on the sliding surfaces. For the case of ZnDTP and ZnDTP+GMO lubrication, the tribofilm produced mainly consist of hydrocarbon, Zinc, Sulphur and Phosphorus elements. The tribofilm for these two types of oil then generates thin and smooth surface between the sliding surfaces. The UV irradiated DLC however exhibits thicker tribofilm thickness compared to the as-deposited DLC. This represents that the dangling bond on graphite like layer attracted more beneficial wear and friction reduction additives elements to affix on its surface which then reflected to the result of lower friction for the UV irradiated DLC.

ZnDTP+MoDTC on the other hand, produced thicker tribofilm compared to the other two previous lubricant oils. The tribofilm comprise of hydrocarbon, Zinc, Sulphur and Molybdenum elements. Compared to the as-deposited DLC, tribofilm thickness on SUJ2 ball for the UV irradiated DLC was thinner which probably due to the lower amount of Sulphur attached on the ball. The same trend of reduction of element attachment such as Sulphur and Molybdenum can also be seen on the on the UV irradiated DLC disk. This indicates that the graphite like layer produced by the UV irradiation process is capable to reduce the ability of wear accelerating elements in MoDTC such as Molybdenum and Sulphur to attach on the DLC surface contributing to lower friction and wear for the UV irradiated DLC [10, 11].

\section{Conclusions}

In this study, the friction characteristics of as-deposited and UV irradiated a-C:H coating was evaluated by AFM, nanoindentation hardness test, ellipsometery, Zygo, and EDS-SEM surface analysis equipment to understand the effect of UV irradiation to a-C:H DLC under four different type of additives added lubricant oils. The conclusions can be summarized as follows:

(1) Friction coefficients of UV irradiated a-C:H coatings exhibited lower friction coefficient compared to the asdeposited a-C:H in all four type of additives added lubricant oils with the highest reduction in ZnDTP oil, followed by $\mathrm{ZnDTP}+\mathrm{MoDTC}$ and Base oil and the least reduction in ZnDTP+GMO oil.

(2) UV irradiation helped to generate thicker tribofilm on both UV irradiated a-C:H disks and its counterpart material SUJ2 balls thanks to the existence of dangling bonds and graphite like layer on the topmost surface of UV irradiated a-C:H disks that caused the tribofilm to stick more on both UV irradiated a-C:H disks and SUJ2 balls instead of only on SUJ2 balls as in as-deposited a-C:H disk.

(3) Base oil showed an increase of tribofilm area which possibly produced by graphite like layer from UV process reacted with Base oil attached on both sliding surfaces, however due to no beneficial additives added resulting the highest friction coefficient among all others.

(4) Both ZnDTP and ZnDTP+GMO oils showed near identical analysis result. Both showed low tribofilm height and area yet thicker on the case of UV irradiated a-C:H, producing smooth surface that had low roughness between sliding surface.

(5) ZnDTP+MoDTC oil formed thick tribofilm between sliding surface. UV irradiation has helped to reduce wear on a-C:H disk by reducing portion of Mo and S from MoDTC that accelerates wear. The tribofilm thickness for the case of UV irradiated a-C:H was slightly lower, but the reduced wear has helped to further reduce the friction coefficient.

\section{Acknowledgements}

This work was supported by Council for Science, Technology and Innovation (CSTI), Cross ministerial Strategic Innovation Promotion Program (SIP), "Innovative Combustion Technology" (Funding agency: JST). The authors would also like to thank Universiti Teknikal Malaysia Melaka (UTeM) and the Ministry of Higher Education (MOHE), Malaysia, for the financial support under scholarship of Skim Latihan Akademik IPTA.

\section{References}

[1] Holmberg, K., Andersson, P. and Erdemir, A., "Global Energy Consumption due to Friction in Passenger Cars," Tribology International, 47, 2012, 221-234.

[2] Tasdemir, H. A., Tokoroyama, T., Kousaka, H., Umehara, N. and Mabuchi, Y., "Influence of Zinc Dialkyldithiophosphate Tribofilm Formation on the Tribological Performance of Self-Mated DiamondLike Carbon Contacts under Boundary Lubrication," Thin Solid Films, 562, 2014, 389-397.

[3] Tasdemir, H. A., Wakayama, M., Tokoroyama, T., Kousaka, H., Umehara, N., Mabuchi, Y. and Higuchi, T., “Ultra-Low Friction of Tetrahedral Amorphous Diamond-Like Carbon (Ta-C DLC) under Boundary Lubrication in Poly Alpha-Olefin (PAO) with Additives," Tribology International, 65, 2013, 286-294.

[4] Vengudusamy, B., Green, J. H., Lamb, G. D. and Spikes, H. A., "Tribological Properties of Tribofilms Formed from ZDDP in DLC/ DLC and DLC/Steel Contacts," Tribology International, 44, 2, 2011, 165-174.

[5] Vengudusamy, B., Green, J. H., Lamb, G. D. and Spikes, H. A., "Influence of Hydrogen and Tungsten Concentration on the Tribological Properties of DLC/DLC Contacts with ZDDP," Wear, 298-299, 1, 2013, 109-119.

[6] Equey, S., Roos, S., Mueller, U., Hauert, R., Spencer, N. D. and Crockett, R., "Tribofilm Formation from ZnDTP on Diamond-Like Carbon," Wear, 264, 3-4, 2008, 316-321.

[7] Topolovec-Miklozic, K., Lockwood, F. and Spikes, H., "Behaviour of Boundary Lubricating Additives on DLC Coatings," Wear, 265, 11-12, 2008, 1893-1901.

[8] Kalin, M., Vižintin, J., Barriga, J., Vercammen, K., Van. Acker, K. and Arnšek, A., “The Effect of Doping Elements and Oil Additives on the Tribological Performance of Boundary-Lubricated DLC/DLC Contacts," Tribology Letters, 17, 4, 2004, 679-688.

[9] Podgornik, B., Jacobson, S. and Hogmark, S., "DLC Coating of Boundary Lubricated Components-Advantages of Coating One of the Contact Surfaces rather than Both or None," Tribology International, 36, 11, 2003, 843-849.

[10] Sugimoto, I., "Mechanism on Specific Wear of DLC Film in Engine 
Oil with Mo-DTC," Transactions of the Japan Society of Mechanical Engineers Series A, 78, 786, 2012, 213-222 (in Japanese).

[11] Haque, T., Morina, A. and Neville, A., "Influence of Friction Modifier and Antiwear Additives on the Tribological Performance of a Non-Hydrogenated DLC Coating," Surface and Coatings Technology, 204, 24, 2010, 4001-4011.

[12] Tung, S. C. and Gao, H., “Tribological Characteristics and Surface Interaction between Piston Ring Coatings and a Blend of EnergyConserving Oils and Ethanol Fuels," Wear, 255, 7-12, 2003, 1276 1285.

[13] Kosarieh, S., Morina, A., Lainé, E., Flemming, J. and Neville, A., “The Effect of MoDTC-Type Friction Modifier on the Wear Performance of a Hydrogenated DLC Coating," Wear, 302, 1-2, 2013, 890-898.

[14] Ohara, K., Hanyuda, K., Kawamura, Y., Omura, K., Kameda, I., Umehara, N. and Kousaka, H., "Analysis of Wear Track on DLC Coatings after Sliding with MoDTC-Containing Lubricants," Tribology Online, 12, 3, 2017, 110-116.

[15] Vengudusamy, B., Green, J. H., Lamb, G. D., and Spikes, H. A., "Behaviour of MoDTC in DLC/DLC and DLC/Steel Contacts," Tribology International, 54, 2012, 68-76.

[16] Kosarieh, S., Morina, A., Flemming, J., Laine, E. and Neville, A., "Wear Mechanisms of Hydrogenated DLC in Oils Containing MoDTC," Tribology Letters, 64, 1, 2016.

[17] Haque, T., Morina, A., Neville, A., Kapadia, R. and Arrowsmith, S., "Effect of Oil Additives on the Durability of Hydrogenated DLC Coating under Boundary Lubrication Conditions," Wear, 266, 1-2, 2009, 147-157.
[18] Topolovec-Miklozic, K., Lockwood, F. and Spikes, H., "Behaviour of Boundary Lubricating Additives on DLC Coatings," Wear, 265, 11-12, 2008, 1893-1901.

[19] Minami, I., Furesawa, T., Kubo, T., Nanao, H. and Mori, S. "Investigation of Tribo-Chemistry by Means of Stable Isotopic Tracers: Mechanism for Durability of Monomolecular Boundary Film," Tribology International, 41, 11, 2008, 1056-1062.

[20] Tokoroyama, T., Umehara, N., Hatano, T. and Fuwa, Y., "The Effect of Ultraviolet Light Irradiation on Friction Coefficient of DiamondLike Carbon Coating under Lubrication," Journal of Japanese Society of Tribologists, 56, 4, 2011, 256-263 (in Japanese).

[21] Tokoroyama, T., Goto, M., Umehara, N., Nakamura, T. and Honda, F., "Effect of Nitrogen Atoms Desorption on the Friction of the $\mathrm{CNx}$ Coating against $\mathrm{Si}_{3} \mathrm{~N}_{4}$ Ball in Nitrogen Gas," Tribology Letters, 22, 3, 2006, 215-220.

[22] Zhang, M., Pan, L. and Nakayama, Y., "Structural Modifications of Hydrogenated Amorphous Carbon Nitride due to Ultraviolet Light Irradiation and Thermal Annealing," Journal of Non-Crystalline Solids, 266-269 B, 2000, 815-820.

[23] Gadallah, K. A. K., Mutschke, H. and Jäger, C., “UV Irradiated Hydrogenated Amorphous Carbon (HAC) Materials as a Carrier Candidate of the Interstellar UV Bump at $217.5 \mathrm{~nm}$," Astronomy and Astrophysics, 528, 2011, A56.

[24] Ji, L., Li, H., Zhao, F., Quan, W., Chen, J. and Zhou, H., "Influences of Ultraviolet Irradiation on Structure and Tribological Properties of Diamond-Like Carbon Films," Applied Surface Science, 255, 20, 2009, 8409-8413. 